\title{
ONE-STEP SYNTHESIS TO ENHANCE THE ACIDITY OF A BIOCARBON-BASED SULFONATED SOLID ACID CATALYST
}

\author{
Yulia Nurul Ma'rifah ${ }^{1}$, Iryanti Fatyasari Nata ${ }^{1 *}$, Hesti Wijayanti ${ }^{1}$, Agus Mirwan $^{1}$, Chairul \\ Irawan $^{1}$, Meilana Dharma Putra ${ }^{1}$, Hidetaka Kawakita ${ }^{2}$ \\ ${ }^{1}$ Chemical Engineering Study Program, Lambung Mangkurat University, Banjarbaru 70714, Indonesia \\ ${ }^{1}$ Department of Chemistry and Applied Chemistry, Saga University, Saga 840-8502, Japan
}

(Received: July 2018 / Revised: October 2018 / Accepted: April 2019)

\begin{abstract}
The main purpose of this study is to produce and generate a solid acid catalyst from biomass with high reactivity that can be used in catalytical reactions such as hydrolysis, and is environmentally friendly and reusable. A biocarbon-based sulfonated catalyst was prepared by the carbonization of palm empty fruit bunches (PEFB), followed by sulfonation. In order to enhance the acidity of the biocarbon, different concentrations of hydroxyethylsulfonic acid were added to the solution during sulfonation at $180^{\circ} \mathrm{C}$ for $4 \mathrm{~h}$ in a Teflon stainless steel autoclave. The $\mathrm{H}^{+}$ion capacity of the biocarbon-sulfonated acid catalyst (BSC) was increased twofold $(3.57 \mathrm{mmol} / \mathrm{g})$ in the presence of $10 \%$ of hydroxyethylsulfonic acid and $10 \%$ of acrylic acid. XRay Fluorescence (XRF) analysis showed that the $\mathrm{BC}_{-} \mathrm{SO}_{3} \mathrm{H}$ contained $38 \%$ of $\mathrm{S}$. The original structure of the PEFB after carbonization disintegrated from the fibrous materials onto porous carbon. The crystalline index (CrI) of the PEFB significantly decreased to about $32 \%$ and a wide broad peak of a X-Ray Diffraction (XRD) pattern of around 20-30 were observed, which shows that an amorphous biocarbon structure had been identified. Fourier Transform Infra-Red (FT-IR) analysis confirmed that the $-\mathrm{SO}_{3} \mathrm{H}, \mathrm{COOH}$ and $-\mathrm{OH}$ functional groups were deposited on the carbon due to specific peaks at around $1180 \mathrm{~cm}^{-1}, 1724 \mathrm{~cm}^{-1}$ and $3431 \mathrm{~cm}^{-1}$, respectively. Decomposition of the sulfonic groups on the biocarbon-sulfonated solid catalyst was observed from $227.9^{\circ} \mathrm{C}$, as it shown by thermal gravimetric analysis (TGA).
\end{abstract}

Keywords: Acid catalyst; Biocarbon; Palm empty fruit bunch; Sulfonated; Sulfonation

\section{INTRODUCTION}

Palm is one of the most important commodities in Indonesia due to its rapid development. The major product from the palm industry is Crude Palm Oil (CPO), but with its increasing production, the waste, that takes the form of empty fruit bunches, has increased. Nowadays, biomass and industrial waste have become very interesting issues as aspects of catalyst development, both in research and from the technical point of view, due to their valuable merit of industrial waste (Guerrero-Pérez et al., 2006; Kusrini et al., 2018). Biomass energy is an ideal clean and renewable energy source, characterized by its wide range of sources, low prices, strong reproducibility and less pollution creation (Wenjing et al., 2018).

In the using of solid acid catalysts, they are easy and efficient when separated from their products, are reusable and it is possible to apply them in wide of applications, but most such catalysts developed are expensive and quite difficult to prepare (Okuhara, 2002).

\footnotetext{
*Corresponding author's email: ifnata@ulm.ac.id, Tel. +62-812-57038675, Fax. +62-511-4773858
} Permalink/DOI: https://dx.doi.org/10.14716/ijtech.v10i3.2924 
Recently, work on sulfonated solid acid catalysts has attracted great attention from researchers for the hydrolysis reaction of cornstarch (Nata et al., 2015; Nata et al., 2017b) and biodiesel production from waste cooking oil (Zong et al., 2007; Nata et al., 2017a). Performance in the reaction of carbon-derived catalysts is dependent on the precursor as raw materials for carbon production and treatment processes (Tao et al., 2015). From the point of view of "green chemistry", the sulfonated carbon catalyst has emerged as a promising solid acid catalyst (Jiang et al., 2012).

Theoretically, at low carbonization $\left(400-600^{\circ} \mathrm{C}\right)$, biomass generates a highly cross-linked, multi-ringed, aromatic structure anchored to lignin that can be easily functionalized with catalytically active acidic groups by slow pyrolysis (Kastner et al., 2012). Generally, a two-step process is involved in the production of sulfonated carbonaceous materials. Saccharide is incompletely carbonized at a temperature of $>400^{\circ} \mathrm{C}$ for $>15 \mathrm{~h}$ under an inert atmosphere. A large amount of sulphuric acid use in the sulfonation process at a high temperature for the inactive surface of carbonaceous material (Zong et al., 2007). This process uses hazardous material and a large amount of harmful waste is produced; moreover, the carbon in the concentrate sulphuric also needs special attention for its separation and treatment.

Hydrothermal carbonization (HTC) is a thermochemical process capable of converting wet biomass into a carbon-enriched solid as hydrochar. The HTC process consists of several reactions conducted both in series and in parallel, including hydrolysis, dehydration, decarboxylation, condensation and aromatization (Merzari et al., 2018). HTC is process which involves the decomposition of several carbohydrates in aqueous solution at $180^{\circ} \mathrm{C}$. This method is cheap, mild and environmental friendly, as no organic solvents, catalysts or surfactants are used (Titirici et al., 2007). In a previous study, Xiao et al. (2010) performed hydrothermal treatment with hydroxyethylsulfonic acid as a sulfonate agent to produce carbon from glucose and used it for an esterification process in order to examine its catalytic ability. However, this procedure only achieved $1.7 \mathrm{mmol} / \mathrm{g}$ of acidity and still owned little of functional groups. Therefore, to generate carbonaceous material loaded with carboxylic groups, known as an active group that participates in the reaction, acrylic acid was added (Bautista-Toledo et al., 2005). In order to produce a high content of functional groups on the carbon material, it is possible to modify the surface by a one-step HTC process for sulfonation and thus improve the acidity of the carbon.

This work focuses on the effect of hydroxyethylsulfonic acid concentration and the addition of acrylic acid during the hydrothermal process. Therefore, the characterization of aspects such as acidity, morphological structure, crystalline structure, functional groups and thermal gravimetric analysis was investigated.

\section{METHODS}

\subsection{Materials}

The raw material as a carbon source for the catalyst is palm empty fruit bunches, collected from PT. Perkebunan Nusantara XIII, South Kalimantan, Indonesia. Citric acid $\left(\mathrm{C}_{6} \mathrm{H}_{5} \mathrm{Na}_{3} \mathrm{O}_{7} .2 \mathrm{H}_{2} \mathrm{O}\right)$, acrylic acid $\left(\mathrm{C}_{3} \mathrm{H}_{4} \mathrm{O}_{2}\right)$, hydroxyethylsulfonic acid $\left(\mathrm{C}_{2} \mathrm{H}_{6} \mathrm{O}_{4} \mathrm{~S}\right)$, sodium cloride $(\mathrm{NaCl})$, sodium hydroxide $(\mathrm{NaOH})$, oxalic acid $\left(\mathrm{H}_{2} \mathrm{C}_{2} \mathrm{O}_{4}\right)$, chloride acid $(\mathrm{HCl})$, methanol $\left(\mathrm{CH}_{3} \mathrm{OH}\right)$, and phenolphthalein were used in analytical standard and purchased from Sigma-Aldrich, St. Louis, USA.

\subsection{Synthesis of a Biocarbon-sulfonated Solid Acid Catalyst}

A biocarbon-sulfonated solid acid catalyst was conducted in line with Xiao et al. (2010) through one-step hydrothermal treatment with some modification. Empty fruit bunches were heated in a furnace at $350^{\circ} \mathrm{C}$ for $1 \mathrm{~h}$, producing carbon meshed up to $60 \mathrm{mesh}$. The obtained 
carbon material was mixed with hydroxyethylsulfoic acid at concentrations of 10, 20 and 30\% $\mathrm{v} / \mathrm{v}, 1.5 \mathrm{~g}$ of citric acid, $1.5 \mathrm{~mL}$ of acrylic acid and $30 \mathrm{~mL}$ of deionized (DI) water poured into a $50 \mathrm{~mL}$ Teflon-lined stainless steel autoclave, then heated for $4 \mathrm{~h}$ at $180^{\circ} \mathrm{C}$. A black carbon material was produced, which was then washed with DI water and $50 \%$ of methanol twice. The biocarbon-sulfonated solid acid catalyst (BSC) was obtained after drying at $80^{\circ} \mathrm{C}$ for $6 \mathrm{~h}$ in an oven. The four different types of carbon particle produced were biocarbon without sulfonation, and carbon with sulfonation containing 10\%, 20\% and 30\% of hydroxyethylsulfonic acid, namely BC, and BSC-1, BSC-2, and BSC-3, respectively.

\subsection{Calculation of Acid Content}

The Brǿnsted acid content in the sample was measured by neutralization titration (Onda et al., 2008). Carbon material $(50 \mathrm{mg})$ was added into a $2 \mathrm{M} \mathrm{NaCl}(25 \mathrm{~mL})$ solution at room temperature and stirred for $5 \mathrm{~h}$. It was then filtered and a clear solution of supernatant was obtained; phenolphthalein was added and then titrated with $0.1 \mathrm{M} \mathrm{NaOH}$ to determine the acid content.

\subsection{Characterization}

Observation of the morphological structure image of the ciocarbon was obtained by a scanning electron microscope (SEM) using JEOL, JSM-6500 LV equipment. The functional groups on the surface of the material were detected by Fourier transform infrared spectrometry (FT-IR, Bio-rad, Digilab FTS-3500) at a wavelength range of $4000-400 \mathrm{~cm}^{-1}$ and a scan rate of 8 . X-ray diffraction (XRD) analysis was conducted on an X-ray diffractometer using $\mathrm{Cu} \mathrm{K} \alpha$ radiation (Rigaku D/MAX-B) with $2 \theta\left(10-40^{\circ}\right)$ at a scan rate of $2^{\circ} \mathrm{min}^{-1}$ and with voltage and current of $40 \mathrm{kV}$ and $100 \mathrm{~mA}$, respectively. Thermal gravimetric analysis (TGA) performance using a Perkin Elmer, Diamond TG/DTA was conducted from $30^{\circ} \mathrm{C}-600^{\circ} \mathrm{C}$ in a nitrogen atmosphere at a heating rate of $10^{\circ} \mathrm{C} / \mathrm{min}$. The remaining material content in the sample was calculated by mass change from the corresponding TGA curves.

\section{RESULTS AND DISCUSSION}

The PEFB in its original form turned to black carbon after carbonization, which was followed by sulfonation via hydrothermal treatment. Hydrothermal carbonization is a method which is an attractive mild preparation of carbons with special properties. The accessible external surface is densely functionalized with polar groups, such as carboxylic and hydroxyl, and confers them high hydrophilicity and susceptibility to chemical modification (Fraile et al., 2012). The treatment of carbon materials under HTC increases or changes their solubility; melts any crystalline parts; accelerates the physical and chemical interaction between reagents and the solvents, facilitating ionic and acid reactions; and leads to carbonaceous structure formation (Hu et al., 2010). A schematic diagram of the preparation of a biocarbon-sulfonated solid acid catalyst is shown in Figure 1.

It is known that during the carbonization process, lignin will breaks in to partial decompose, then hemicellulose and cellulose would decompose through thermal homolysis, hydrolysis, dehydration, and rearrangement of molecular reactions to form a polymerized aromatic structure, then next process is bounding sulfonic groups to biocarbon materials during hydrothermal treatment. The arrangement of biocarbon material by dehydration in the first step, then allows sulfonic and carboxylic acid groups will induced on carbon materials, subsequently providing hydroxyl functional groups for intermolecular dehydration. In this case, hydroxyethylsulfonic acid was used as a functional molecule to introduce sulfonic groups to the biocarbon material, and carbonyl groups were supplied by citric acid, which helped obtain carbon with high acidity (Xiao et al., 2010). 


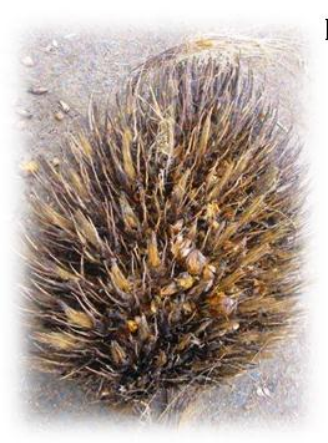

PEFB homolysis, hydrolysis,
dehydration

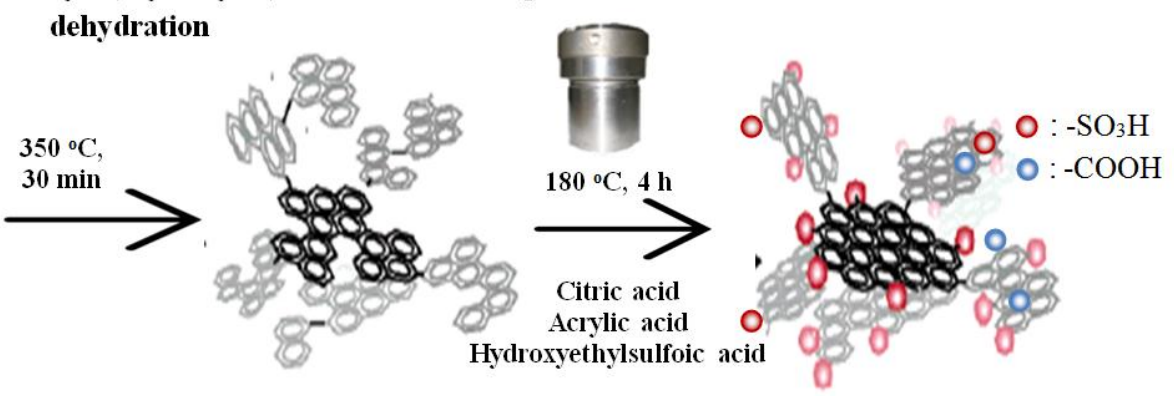

Biocarbon electrophilic substitution

Biocarbon Sulfonated Solid Acid Catalyst (BSC)

Figure 1 Schematic diagram of the preparation of a biocarbon-sulfonated solid acid catalyst from PEFB

Moreover, the addition of acrylic acid as a co-monomer in hydrothermal treatment causes the escalation of catalyst acidity. The acrylic acid induction for the hydrothermal carbonization process could achieved for product with rich of carboxylic groups on the surface, which was known that carboxylic groups more active than sulfonic groups and participate in the reaction instead of sulfonic groups (Demir-Cakan et al., 2009). The presence of sulfonic groups is reached by the reaction of the sulfonating agent and the polysiclic aromatic rings of biocarbon that make up the new structure, through electrophilic substitution (Aldana-Pérez et al., 2012; Lokman et al., 2016).

Table 1 shows the acidity and $\mathrm{S}$ content base on X-Ray fluorescence for different types of biocarbon-sulfonated solid acid catalyst. The addition of $10 \%$ of hydroxyethylsulfonic acid increased level of S content by around 38\%; however, the biocarbon acidity decreased when $>10 \%$ hydroxyethylsulfonic acid was added. This was probably due to the competitiveness of each functional group when binding with biocarbon during hydrothermal treatment. The more the hydroxyethylsulfonic acid used in the sulfonation process, the higher the $\mathrm{S}$ content accommodated on the carbonaceous materials, resulting in more acidic groups such as carboxyl, carbonyl and hydroxyl not being able to bind with the biocarbon, whereas these acid groups acted as suppliers of $\mathrm{H}^{+}$ions, which helped produce biocarbon with high acidity. This explains the decrease in acid capacity for BSC-2 and BSC-3 compared to BSC-1. A higher acidity content in the solid acid catalyst will improve its reactivity during reactions such as hydrolysis and esterification. In the case of the hydrolysis reaction, the $\mathrm{H}^{+}$ions in the catalyst will break the polymer bond of amylose.

Table 1 Acidity and S content of different types of biocarbon solid acid catalyst

\begin{tabular}{ccc}
\hline Sample & Acidity $(\mathrm{mmol} / \mathrm{g})$ & S content $(\%)$ \\
\hline BC & 0.209 & - \\
BSC-1 & 3.569 & 38.0 \\
BSC-2 & 2.380 & 46.8 \\
BSC-3 & 2.712 & 54.4 \\
\hline
\end{tabular}

Biocarbon morphological characterization of the solid acid catalyst was conducted in order to predict the physical and chemical properties of the material. As shown in Figure 2a, the PEFB had a fibrous shape with a smooth surface, while Figure $2 b$ shows the structure after carbonization. In comparison, Figures $2 \mathrm{c}, 2 \mathrm{~d}$ and $2 \mathrm{e}$ show difference surface morphology of biocarbon, the sulfonation process in the presence of hydroxyethylsulfonic and acrylic acid 
were genetared scattered shape form, but more aggregated. Presumably, hydroxyethylsulfonic acid acted as an agent that disintegrated the fibrous materials onto the porous carbon, which allowed the sulfonate groups to attach to the surface of the carbon. In addition, more particles were formed with a smaller size during dehydration, and polymerization caused the surface of the material to be no longer smooth due to the change in the material morphology induced by the addition of hydroethylsulfonic and acrylic acid.

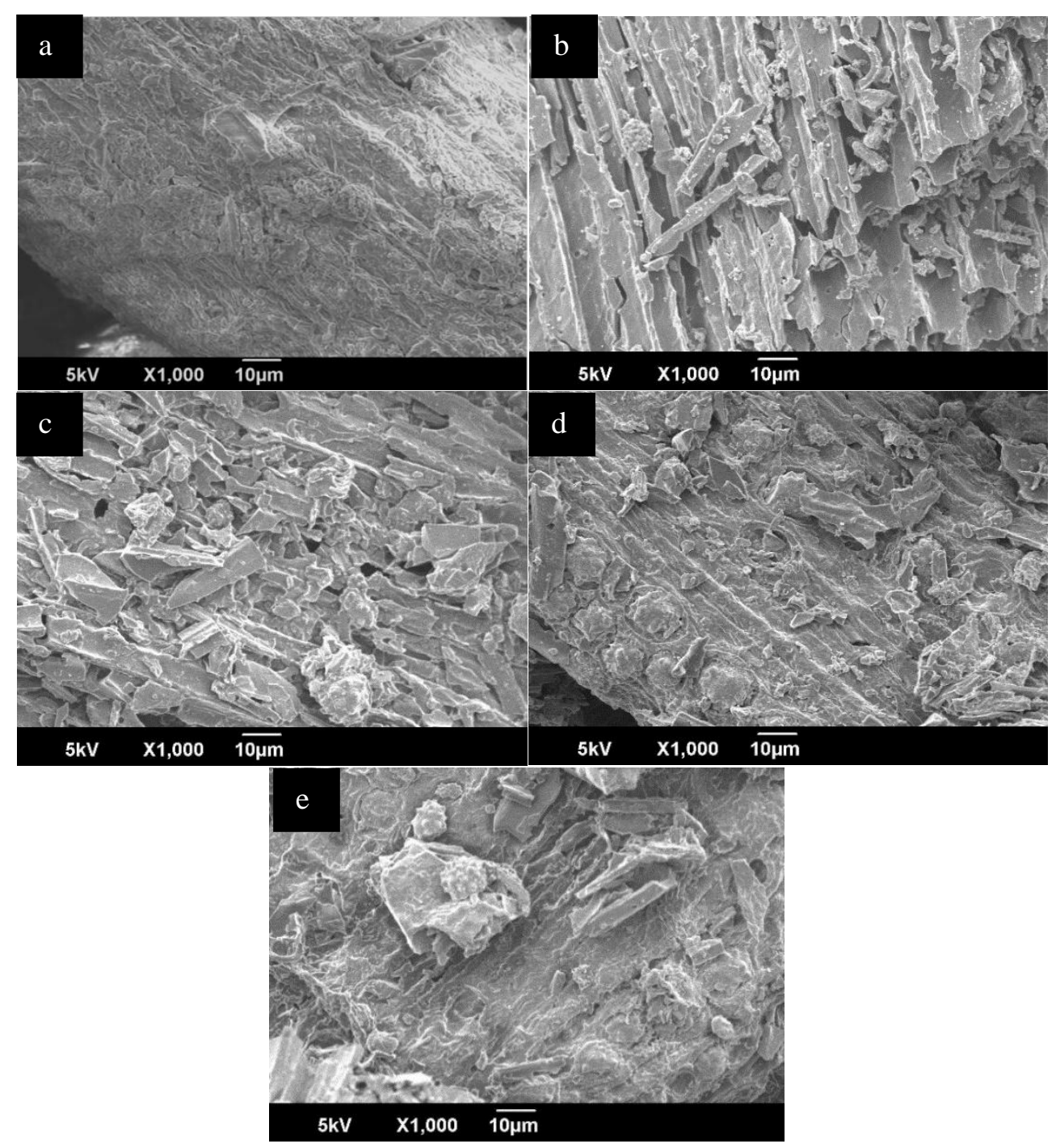

Figure 2 SEM images of: (a) PEFB; (b) BC; (c) BSC-1; (d) BSC-2; (e) BSC-3

Figure 3 shows the XRD pattern for the material whose crystalline PEFB index significantly decreased by around $22.38 \%$. The BC, BSC-1, BSC-2 and BSC-3 formed a wide-broad peak pattern of around $2 \theta=20-30^{\circ}$, which shows the amorphous structure of carbon (Okamura et al., 2006). These data prove that treatment at different concentrations of acrylic acid does not effects to the amorphous structure of the carbon. The reduction in the crystalline index (CrI) indicates that the crystalline structure transformed into carbon due to the carbonization process which involved degradation of lignin, hemicellulose and cellulose. 


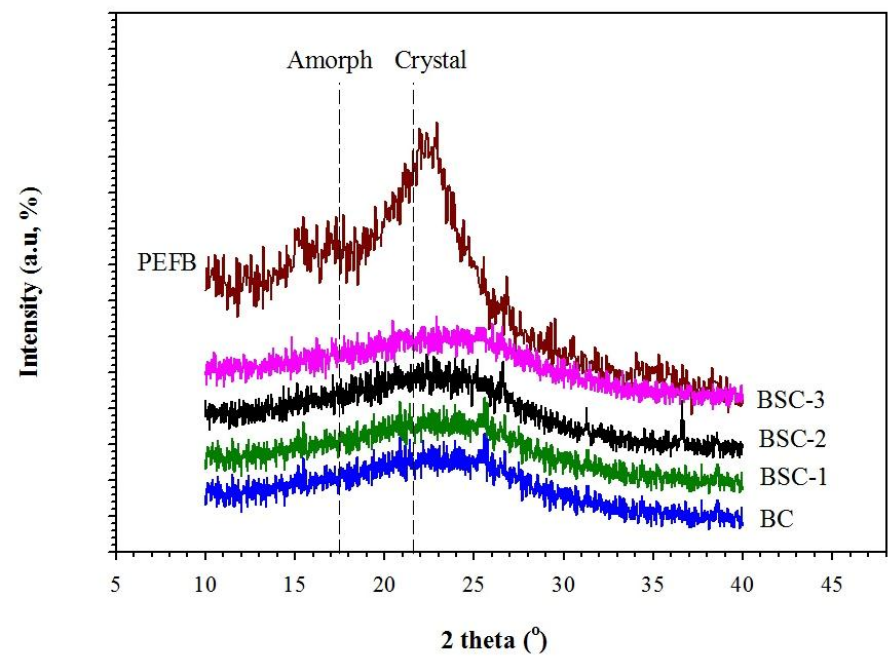

Figure 3 XRD patterns of PEFB, BC, BCS-1, BCS-2, and BCS-3

FT-IR measurement was made to identify the functional groups on the material. Absorption bands of $-\mathrm{OH}$ stretching at $3450 \mathrm{~cm}^{-1}$, $-\mathrm{OH}$ bending at $1000-1300 \mathrm{~cm}^{-1}$ and $\mathrm{C}=\mathrm{C}$ double bonds at $1608 \mathrm{~cm}^{-1}$ were found in all the samples (Zong et al., 2007). The presence of a sulfonate absorption band at $1207 \mathrm{~cm}^{-1}$ and $\mathrm{C}=\mathrm{O}$ double bonds at $1720 \mathrm{~cm}^{-1}$, which indicate carboxylic groups, was identified for BSC-1, BSC-2, BSC-3, as shown in Figure 4. The different concentrations of hydroxyethylsulfonic acid give different intensity peaks for the sulfonate group, a higher concentration, and sharper peaks were formed. This observation is related to the XRF results. Furthermore, FT-IR analysis proved that the biocarbon materials were successfully sulfonated during the hydrothermal process with the addition of hydroxyethylsulfonic acid. The presence of sulfonic acid groups $\left(-\mathrm{SO}_{3} \mathrm{H}\right)$ on the carbon will change the $\mathrm{pH}$ of the surface, therefore they also change the adsorption characteristics and makes these carbons suitable for the application as heterogeneous solid acid catalysts (Fraga et al., 2016).

In order to understand the typical degradation of PEFB and the impact of sulfonation on the thermal stability of biocarbon-sulfonated solid acid catalysts, thermal gravimetric analysis was conducted. In Figure 5, the gravimetric analysis of all the materials carbonized up to $600^{\circ} \mathrm{C}$ is shown. The PEFB starts the dehydration of water at $74.4^{\circ} \mathrm{C}$, followed by the decomposition of lignin and hemicellulose at $332.5^{\circ} \mathrm{C}$. Major decomposition of the biocarbon material, including the sulfonated solid catalyst, was observed from $227.9^{\circ} \mathrm{C}$ for the sulfonic group.

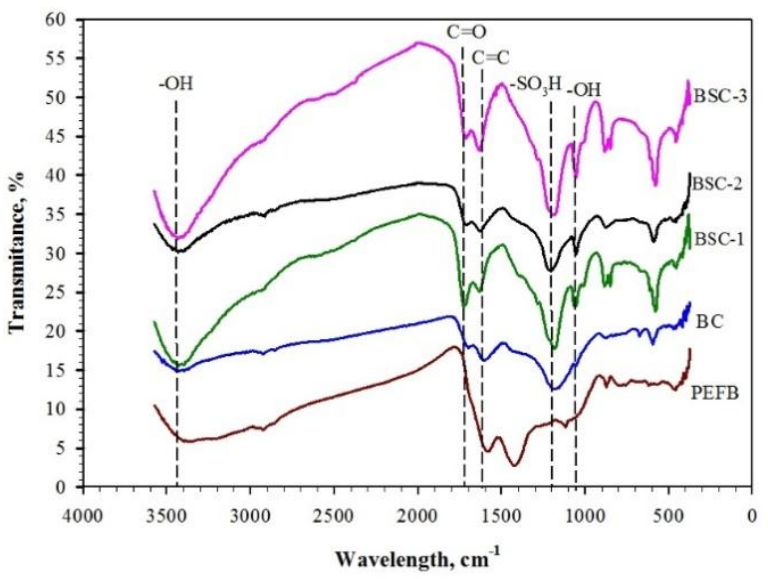

Figure 4 FT-IR spectra of PEFB, BC, BSC-1, BSC-2, and BSC-3 


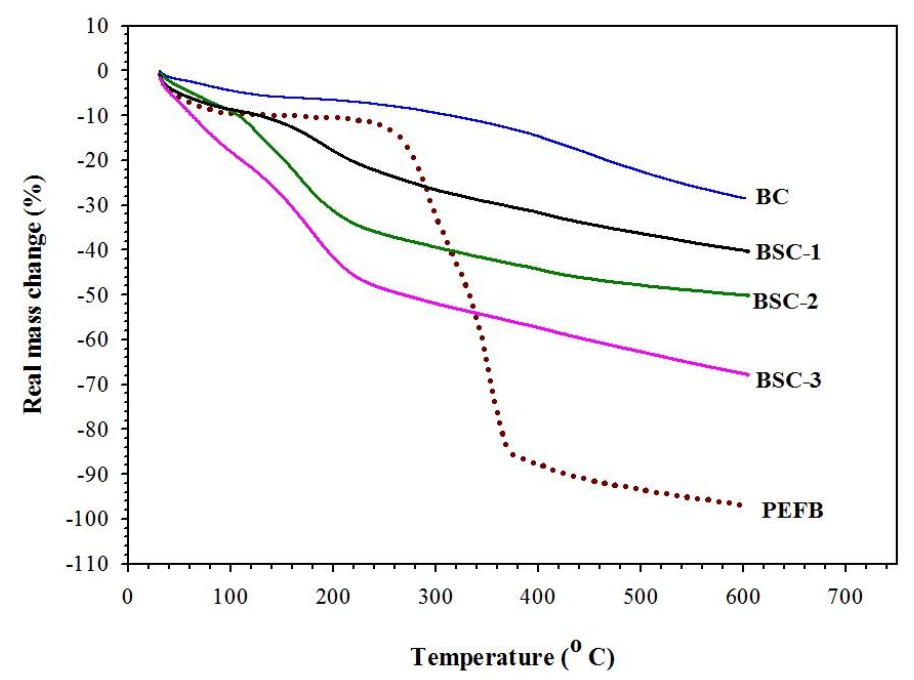

Figure 5 TGA curves of PEFB, BC, BSC-1, BSC-2, BSC-3

Sulfonation of the biocarbon lowered the temperature at which mass loss occurred and partially oxidized the structure, reducing thermal stability (Kastner et al., 2012). A higher concentration of sulfonic acid will result in more mass loss on the TGA curve, as for BSC-1, BSC-2 and BSC3 at about $40 \%, 50 \%$ and $67 \%$, respectively. This phenomenon of mass loss indicates that the material contained in the catalyst rapidly diminishes as the temperature increases, and is related to the number of sulfonic groups obtained by the XRF results. It can be concluded that a biocarbon-based solid catalyst sulfonated with a higher amount of sulfonate agent will have a frailer structure and be unstable with alterations in temperature compared to the original biocarbon or the biocarbon catalyst sulfonated with less sulfonate agent.

\section{CONCLUSION}

The strong acid content, rich of sulfonic and carboxylic groups of materials could be easily synthesized by a one-step hydrothermal process using biocarbon from incomplete carbonization of PEFB, and in the presence of hydroxyethylsulfonic, acrylic and citric acid in mild conditions. The simplicity of operation, high activity and stability, low cost of raw materials and reusability are the main features of this original biocarbon-based sulfonated solid acid catalyst, which demonstrates that biocarbon has great potential for green processes in various catalytic applications.

\section{ACKNOWLEDGEMENT}

The authors are grateful for the financial support from International Research Collaboration and Scientific Publication (contract No. 040/UN8.2/PL/2018), Ministry of Research, Technology and Higher Education, Republic of Indonesia.

\section{REFERENCES}

Aldana-Pérez, A., Lartundo-Rojas, L., Gómez, R., Niño-Gómez, M.E., 2012. Sulfonic Groups Anchored on Mesoporous Carbon Starbons-300 and Its Use for the Esterification of Oleic Acid. Fuel, Volume 100, pp. 128-138

Bautista-Toledo, I., Ferro-García, M.A., Rivera-Utrilla, J., Moreno-Castilla, C., Vegas Fernández, F.J., 2005. Bisphenol A Removal from Water by Activated Carbon. Effects of Carbon Characteristics and Solution Chemistry. Environmental Science \& Technology, Volume 39(16), pp. 6246-6250 
Demir-Cakan, R., Baccile, N., Antonietti, M., Titirici, M.-M., 2009. Carboxylate-rich Carbonaceous Materials via One-step Hydrothermal Carbonization of Glucose in the Presence of Acrylic Acid. Chemistry of Materials, Volume 21(3), pp. 484-490

Fraga, A.d.C., Quitete, C.P.B., Ximenes, V.L., Sousa-Aguiar, E.F., Fonseca, I.M., Rego, A.M.B., 2016. Biomass Derived Solid Acids as Effective Hydrolysis Catalysts. Journal of Molecular Catalysis A: Chemical, Volume 422, pp. 248-257

Fraile, J.M., García-Bordejé, E., Roldán, L., 2012. Deactivation of Sulfonated Hydrothermal Carbons in the Presence of Alcohols: Evidences for Sulfonic Esters Formation. Journal of Catalysis, Volume 289, pp. 73-79

Guerrero-Pérez, M.O., Fierro, J.L.G., Bañares, M.A., 2006. Effect of Synthesis Method on Stabilized Nano-scaled Sb-V-O Catalysts for the Ammoxidation of Propane to Acrylonitrile. Topics in Catalysis, Volume 41(1-4), pp. 43-53

Hu, B., Wang, K., Wu, L., Yu, S.-H., Antonietti, M., Titirici, M.-M., 2010. Engineering Carbon Materials from the Hydrothermal Carbonization Process of Biomass. Advanced Materials, Volume 22(7), pp. 813-828

Jiang, Y., Li, X., Wang, X., Meng, L., Wang, H., Peng, G., Wang, X., Mu, X., 2012. Effective Saccharification of Lignocellulosic Biomass Over Hydrolysis Residue Derived Solid Acid under Microwave Irradiation. Green Chemistry, Volume 14(8), pp. 2162-2167

Kastner, J.R., Miller, J., Geller, D.P., Locklin, J., Keith, L.H., Johnson, T., 2012. Catalytic Esterification of Fatty Acids using Solid Acid Catalysts Generated from Biochar and Activated Carbon. Catalysis Today, Volume 190(1), pp. 122-132

Kusrini, E., Supramono, D., Degirmenci, V., Pranata, S., Bawono, A.A., Ani, F.N., 2018. Improving the Quality of Pyrolysis Oil From Co-firing High Density Polyethylene Plastic Waste and Palm Empty Fruit Bunches. International Journal of Technology, Volume 9(7), pp. 1498-1508

Lokman, I.M., Goto, M., Rashid, U., Taufiq-Yap, Y.H., 2016. Sub- and Supercritical Esterification of Palm Fatty Acid Distillate with Carbohydrate-derived Solid Acid Catalyst. Chemical Engineering Journal, Volume 284, pp. 872-878

Merzari, F., Lucian, M., Volpe, M., Andreottola, G., Fiori, L., 2018. Hydrothermal Carbonization of Biomass: Design of a Bench-scale Reactor for Evaluating the Heat of Reaction. Chemical Engineering Transaction, Volume 65, pp. 43-48

Nata, I.F., Irawan, C., Mardina, P., Lee, C.-K., 2015. Carbon-based Strong Solid Acid for Cornstarch Hydrolysis. Journal of Solid State Chemistry, Volume 230, pp. 163-168

Nata, I.F., Putra, M.D., Irawan, C., Lee, C.-K., 2017. Catalytic Performance of Sulfonated Carbon-based Solid Acid Catalyst on Esterification of Waste Cooking Oil for Biodiesel Production. Journal of Environmental Chemical Engineering, Volume 5(3), pp. 2171-2175

Nata, I.F., Putra, M.D., Nurandini, D., Irawan, C., 2017. Facile Strategy for Surface Functionalization of Corn Cob to Biocarbon and Its Catalytic Performance on Banana Peel Starch Hydrolysis. International Journal on Advanced Science Engineering Information Technology, Volume 7(4), pp. 1302-1308

Okamura, M., Takagaki, A., Toda, M., Kondo, J.N., Domen, K., Tatsumi, T., Hara, M., Hayashi, S., 2006. Acid-catalyzed Reactions on Flexible Polycyclic Aromatic Carbon in Amorphous Carbon. Chemistry of Materials, Volume 18(13), pp. 3039-3045

Okuhara, T. 2002. Water-tolerant Solid Acid Catalysts. Chemical Reviews, Volume 102(10), pp. 3641-3666

Onda, A., Ochi, T., Yanagisawa, K., 2008. Selective Hydrolysis of Cellulose into Glucose Over Solid Acid Catalysts. Green Chemistry, Volume 10(10), pp. 1033-1037

Tao, M.-L., Guan, H.-Y., Wang, X.-H., Liu, Y.-C., Louh, R.-F., 2015. Fabrication of Sulfonated Carbon Catalyst from Biomass Waste and Its Use for Glycerol Esterification. Fuel Processing Technology, Volume 138, pp. 355-360 
Titirici, M.-M., Thomas, A., Antonietti, M., 2007. Replication and Coating of Silica Templates by Hydrothermal Carbonization. Adv Funct Mater, Volume 17(6), pp. 1010-1018

Wenjing Han, Xuezhen Li, Shulan Yu, Xiujie Sang, 2018, Catalytic Action of Biomass Carbon Sulfoacid in Fine Organic Synthesis, Chemical Engineering Transaction, Volume 65, pp.547-552

Xiao, H., Guo, Y., Liang, X., Qi, C., 2010. One-step Synthesis of Novel Biacidic Carbon via Hydrothermal Carbonization. Journal of Solid State Chemistry, Volume 183(7), pp. 17211725

Zong, M.-H., Duan, Z.-Q., Lou, W.-Y., Smith, T.J., Wu, H., 2007. Preparation of a Sugar Catalyst and Its Use for Highly Efficient Production of Biodiesel. Green Chemistry, Volume 9(5), pp. 434-437 